\title{
Student Perspectives On Graduate Attributes
}

\author{
Matt Wright ${ }^{1}$, Chris Campbell ${ }^{2}$, Susan Nesbit ${ }^{1}$, Thomas Froese ${ }^{1}$, and Steve Wilton ${ }^{2}$ \\ ${ }^{1}$ University of British Columbia Civil Engineering, ${ }^{2}$ University of British Columbia Electrical \& Computer Engineering \\ matt.wright@alumni.ubc.ca; chriscampbel12@mac.com
}

\begin{abstract}
This paper outlines a survey validation process and presents preliminary findings from a study of Civil and Electrical and Computer engineering graduate perspectives on their program with respect to the Canadian Engineering Accreditation Board (CEAB) Engineering Graduate Attributes. The study's research question was: What breadth and depth of knowledge, as specified by the Engineering Graduate Attributes, do undergraduate engineering students perceive they have achieved? This research is part of a larger research agenda in these departments in UBC engineering to collect data for the ongoing processes of curriculum improvement and CEAB accreditation. While the Civil and Electrical and Computer Engineering departments at UBC collaborated in this study, different survey instruments were produced for each context. This paper focuses primarily on the Civil Engineering Graduate Attributes Survey Tool.
\end{abstract}

Keywords: Graduate Attributes; Survey Development; Continuous Improvement; Reporting; Curriculum Mapping; Accreditation; Student Perspective

\section{INTRODUCTION}

Advancements in how we learn and retain knowledge [1][2][3][4][5] are resulting in calls to redesign educational experiences in higher education [6][7][8][9]. At the Departments of Civil Engineering and Electrical and Computer Engineering at the University of British Columbia, these calls are being met by the development of a conceptual framework for curriculum management where-in program-level learning goals are set [10], vertical and horizontal integration into learning activities of the goals is attempted, and a curriculum management strategy is established. The strategy consists of three primary activities:

1. Annual, and day-to-day management of the curriculum that ensures the curriculum functions well (e.g., class-scheduling, allocating teaching and resources, administration of curricular changes, etc.).

2. Curriculum monitoring and reporting (including reporting to the Canadian Engineering Accreditation Board, the University, and to internal reporting to departmental decision-making bodies such as the re-appointment, promotion, and tenure committees).

3. Curriculum governance, i.e., activities by the departmental decision-making bodies responsible for the quality of the learning within the curriculum. Importantly, these bodies receive and learn from curriculum monitoring.

The social nature of curricular activities suggests the need to collect data from a variety of perspectives during curriculum monitoring. Therefore, in addition to collecting information from faculty members, data that capture the perspective of the engineering profession regarding graduating students, and, importantly, data capturing the student experience, is needed.

The validation of the surveys involved several key steps: a literature review to identify key models of competence for the graduate attributes and similar survey instruments used in other engineering schools; the development of indicators and survey items; the refinement of survey items through student focus groups and expert review; the piloting of a draft survey, an exploratory factor analysis (EFA) to identify problematic items, and a process of item reduction to refine the survey. At the time of writing, confirmatory factor analysis (CFA) is being conducted to determine the fit of the data to the factor structure suggested by EFA. These preliminary findings are compared with those derived from curriculum mapping data in order to identify areas for curriculum improvement. Finally, this paper assesses the strengths and weaknesses of the Civil Engineering Graduate Attributes Survey Tool in providing valid, reliable, and relevant evidence for the purposes of curriculum improvement and CEAB accreditation and outlines further work needed for its full validation. 


\section{SURVEY VALIDATION}

As discussed in the introduction, the creation and piloting of this survey tool was part of broader research agenda in the respective Civil and Electrical and Computer Departments to investigate the coverage of the graduate attributes in the undergraduate programs for the purposes of curriculum improvement and accreditation. Foregoing a long discussion of the overall research design and how this survey fits into the wider research context, this section focuses on the creation and ongoing validation of the survey tool.

\subsection{On Validity and Validation}

The central challenges in developing the survey related to validity: to render the attributes into a measure meaningful to students that covered the constructs or competencies underpinning the attributes in a way that would yield reliable, relevant, and trustworthy findings. The American Psychological Association identifies validity as the fundamental consideration in developing and evaluating tests or surveys and define it as "the degree to which evidence and theory support the interpretation of test (or survey) scores entailed by proposed uses of tests" [1]. Goodwin and Leech (2003) identify sources of such validity evidence:

1) Evidence based on survey content: A form of content-related evidence "based on logical analyses the expert evaluation of the content of the measure, including items, tasks, formats, wording, and processes required of examinees" (p. 183) and the elimination content that results in 'construct irrelevant variance' or 'construct underrepresentation'.

2) Evidence based on response processes: A form of construct-related evidence concerned with "the extent to which the tasks or types of responses required of examinees fit the intended, defined construct" (p. 184) on which the survey items are based.

3) Evidence based on internal structure: A form of construct-related evidence concerned with "the extent to which the items and internal components of a test (or survey) match the defined construct" (p. 184). This type of evidence is related to internal consistency and reliability.

4) Evidence based on relations to other variables: A form of criterion-related validity, meaning the extent to which a measure is related to concrete criteria in the 'real world'. Examples might include the survey's predictive ability of graduate performance in professional contexts or the extent to which survey findings contradict or corroborate with findings from other data sources.

5) Evidence based on the consequences of testing: Evidence in this category "pertains to anticipated and unanticipated consequences (positive or negative) of measurement" (p. 185)[2].

So described, validity evidence extends beyond just the properties of the survey itself to include the proposed use of its findings as well, something that will be important later as the survey data finds its place amongst other sources of data associated with curriculum improvement and accreditation.

The process of developing and validating a survey tool, then, "involves accumulating evidence to provide a sound scientific basis for the proposed score interpretations" [1]. In this study, the practical activities to ensure this validity were guided by established approaches to survey creation and validation [3][4] and involved the following steps: 1) item generation, 2) survey piloting, 3) item refinement and reduction, and 4) garnering additional validity evidence from confirmatory factor analysis. At the time of writing, steps \#1-3 have largely been completed and step \#4 is ongoing.

\subsection{Item Generation}

The Engineering Graduate Attributes were used as the overarching framework to guide survey development with the understanding that a process of interpretation was required before draft survey items could be written. Firstly, where possible, constructs or models of competence for each attribute were identified in research, 'best' practices, recognized standards, and other relevant surveys. Secondly, representative indicators that together provided coverage of attribute's construct or model of competence were identified, adapted, or created. Thirdly, where research, 'best' practices, or recognized standards were found wanting, indicators were provisionally defined or organized using a deductive approach. Finally, items were written, adapted, or adopted in accordance with the indicators.

In the item generation stage, differences emerged in the evolution of items in the Civil and Electrical and Computer Engineering surveys for several reasons: Civil engineering's research goal of linking the items to $\mathrm{BOK}$ items used in previous research and linking data to curriculum mapping, disciplinary content and specialization, degree of reliance on constructs and models of competence from research and recognized standards, and degree of reliance on survey instruments from other sources. 
One example in the development of the Civil graduate attributes survey is that indicators were reworded to map onto Bloom's Taxonomy of Learning Domains and transformed into survey items. The items were further modified in order to resonate within a program-specific audience, including cues such as course codes.

Between four and six items were developed for each attribute for a total of approximately 60 items for the survey's first draft. This number of items was selected to balance survey length with the need to cover the content or construct of each attribute and ensure internal consistency. Expert reviews of these items in the respective engineering departments resulted in item elimination, new items, and item revisions (i.e., content, wording, and focus). The result was the first survey draft.

In the case of the Civil survey development, student focus groups were provided with these refined items from the expert focus group plus additional items identified from other surveys, constructs, and models of competence. Students were asked to reduce these items to a smaller number of items which best covered the attribute as a group using a process of deduction. This exercise helped to identify problems in item wording and content and eliminate or refine items that were conceptually inconsistent with student perceptions and experiences in the program.

In the Civil survey, question stems were developed in the form of student perception of ability and were worded "I am able to...". A five-point Likert scale was used for student responses of "strongly agree", "agree", "neutral", "disagree", and "strongly disagree" (Figure 1). The new survey items and format was administered in an additional pre-piloting focus group and the new wording was found to effectively elicit student perceptions of ability in a majority of focus group participants.

\subsection{Survey Piloting}

The Civil survey was piloted with fourth year students and the two Electrical and Computer surveys piloted with second, third and fourth year students. The total population of the programs are 187 student in $4^{\text {th }}$ year Civil and 289, 262 and 238 students in $2^{\text {nd }}$, $3^{\text {rd }}$, and $4^{\text {th }}$ year Electrical and Computer, respectively. Both programs attempted to ensure a large response rate through mass email communication and extensive promotion. Civil Engineering also employed in situ, paper option for survey respondents and managed to do a one-time large class administration. There was also reminder emails sent out to maximize survey reach and to stimulate and maintain interest in the survey.

\subsection{Initial Refinement and Reduction}

Survey validation processes commonly employ factor analysis using statistical software as a method of refining surveys and garnering validity evidence. There are two types of factor analysis used in survey validation: Exploratory Factor Analysis (EFA), which is used to explore the factor structure (i.e., the constructs underlying the survey items) of an instrument and identify problematic items, and Confirmatory Factor Analysis (CFA), which is used fix specific items to a defined factor structure and calculate the fit of the data to that structure. A commonly recognized procedure for survey development and validation is to pilot a first draft of the survey, perform an exploratory factor analysis on the data to identify the factor structure and refine and eliminate items, pilot the second draft of the survey, and then perform confirmatory factory analysis to confirm the factor structure and identify the goodness of fit of that factor structure to the data [4]. Hence, survey validation requires two survey pilots and two analyses because it is not good practice to use the same data for both exploratory factor analysis and confirmatory factor analysis. Survey developers and researchers expect that these procedures, combined with the survey development steps discussed earlier, allow them to claim that the survey and its proposed use are reliable and valid.

While the authors of this paper recognize the standard measurement practice of piloting two successive drafts to ensure the validity of the survey instrument, they also recognize the urgency of collecting data for curriculum improvement and accreditation. As such, a decision was made to use exploratory factor analysis to identify problematic items and to revise or eliminate them for the next year of surveying. The researchers then used confirmatory factor analysis on the same data set to understand goodness or fit of the data to the factor structure of the first survey draft. This at least allows preliminary findings to be reported in this study. In the year that follows, the second draft of the survey will be tested, validated, and the results used for accreditation. The only drawback with this compromise is that the preliminary findings reported here may not be comparable to the data collected next year because the survey instrument will change. At the time of writing, the researchers had completed the exploratory factor analyses and were in the process of doing a confirmatory factor analysis to determine model-data fit.

Russell (2002), Hinkin (1998), and other authors offer guidance in performing exploratory factor analyses and garnering validity evidence: 
1) A minimum sample of 100 cases to accurately reproduce population loadings in exploratory factor analysis and 200 cases for confirmatory factor analysis [6],

2) Principal axis factoring to best reproduce population loadings [5] with Promax rotation to improve fit of correlated factors and reveal uncorrelated factors [6],

3) Parallel analysis in order to identify statistically significant eigenvalues [6][7],

4) Loading of at least three items on each factor with a minimum factor loading of 0.3 with 0.2 greater loading on a factor over other factors [4][6].

5) Cronbach's alpha $\geq 0.8$; and item-to-total correlations $\geq 0.4$ (measures of internal consistency)

\subsection{Principal Axis Factoring - Civil}

Principal axis factoring was performed on the civil engineering survey data to measure internal reliability of the survey items, and to determine the factor loading for each attribute. In theory, survey items should load onto each factor with a degree of liability, and responses should correlate to a specific construct. In the case of the student perception survey, each survey item should align with a specific attribute. Any deviance form this can indicate the following alterations be performed: rewording of survey item for language or coherence, duplication of survey items for more than one attribute, and/or the necessity to remove items as they do not capture student ability for the attribute. From the resulting data, it was identified that the Problem Analysis and Ethics and Equity attributes did not have internal consistency from their current survey items. The survey items must be rewording or modified to create a more cohesive response from students. It may also be possible that students perceive their abilities within these two attributes to be more accurately captured by other graduate attributes. A post-analysis focus group can be employed to flesh out any further discrepancies in the data.

The results from the 'Impact of Engineering on Society and the Environment' attribute were internally reliable, save for one survey item. The indicator was derived from focus group information that felt the statement "Perform a multi-criteria decision analysis for a given civil engineering problem, and select a rational result" captured the essence of their undergraduate curricular experience, however the individual survey item did not load onto the factor as well as the other three items. This may indicate that the multi-criteria decision analysis was not taught to all civil engineering graduates, or students do not feel confident in their ability to perform such an analysis. The results from the 'Professionalism' attribute also demonstrate internal reliability, although one survey item ("Demonstrate professional etiquette and conduct with regards to interpersonal and stakeholder relationships, including non-technical participants") remained as an outlier. This can be partially explained by its likeliness to survey items contained within 'Impact of Engineering' and 'Communication' attributes. Further analysis of the data would be required to confirm this variance.

Students were provided with an excess of survey items for each attribute such that the pilot version could be refined for future use. With four to six items per attribute, items that had either a low reliability score or large deviations could be removed without impacting the construct of each attribute.

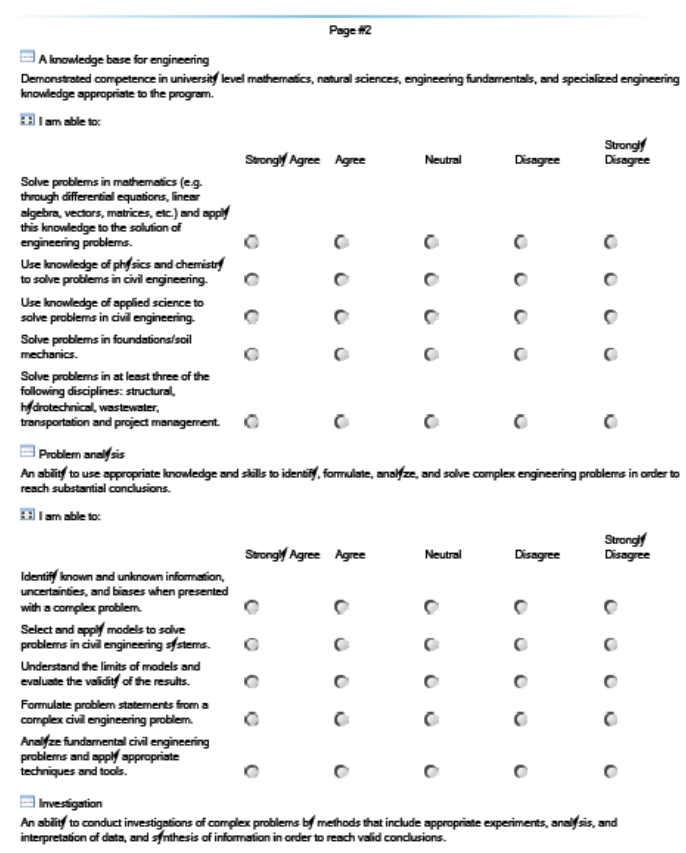

Fig. 1. Civil Survey Design

2.5.1 Principal Axis Factoring Results. From the analyzed data, Cronbach's Alpha was found to be 0.965 , which indicates excellent internal consistency of the items based on George and Mallery (2003). Of the 53 total survey items, only one item (Tools, Item 2) failed to meet the requirement of 0.4 for the itemto-total correlation. The range for the remaining 52 items ranged from 0.425 to 0.684 . 


\subsection{Future Validation Activities}

A complete revision of the survey's first draft based on the exploratory factor analysis and a confirmatory factor analysis on the first draft are now underway. The second draft of the survey will be deployed in 2014 as data collection for the CEAB accreditation begins in earnest. With the second deployment, factor analyses of data is expected to confirm the validity of the survey tool for the purposes of data collection in the form of improved internal consistency and goodness of fit of data with the factor structure of the final survey.

\section{RESULTS}

Civil Engineering had a total survey response rate of $82 \%$ ( 153 respondents) of the $4^{\text {th }}$ year class using the dual implementation method of email and paper. Of this response rate, roughly 25 respondents did not finish the entire survey. This can be broken down into the substituent program specialties of BASc Civil Engineering $(\mathrm{n}=87)$, Minor in Commerce $(\mathrm{n}=9)$, Coop $(n=47)$ and Minor in Environmental $(n=10)$. The breakdown of gender was broken down into gender classification for analysis, which yielded Male response of $81.7 \%(n=125)$ and female response of $18.3 \%(\mathrm{n}=26)$.

Electrical and Computer Engineering had a total survey response rate of $18 \%$ (53 respondents), $28 \%$ (73 respondents) and $24 \%$ (58 respondents) for $2^{\text {nd }}$, $3^{\text {rd }}$, and $4^{\text {th }}$ year students, respectively.

Table 1 summarizes the mean values for each attribute in the student survey. Preliminary analysis of correlations between means may be beneficial, however the values reflect results prior to item reduction.

Table 1: Mean Values for Attributes

\begin{tabular}{|l|ll|l|}
\hline \multicolumn{3}{|c|}{ Attributes } & $\begin{array}{l}\text { Mean } \\
\text { Values }\end{array}$ \\
\hline Knowledge & Civil & $4^{\text {th }}$ year & 1.858 \\
Base for & Elec. \& Comp. & $2^{\text {nd }}$ year & $2.234^{*}$ \\
Engineering & & $3^{\text {rd }}$ year & 1.949 \\
& & $4^{\text {th }}$ year & 2.088 \\
\hline Problem & Civil & $4^{\text {th }}$ year & 1.862 \\
Analysis & Elec. \& Comp. & $2^{\text {nd }}$ year & 2.803 \\
& & $3^{\text {rd }}$ year & 2.216 \\
& & $4^{\text {th }}$ year & 2.255 \\
\hline Investigation & Civil & $4^{\text {th }}$ year & 1.948 \\
& Elec. \& Comp. & $2^{\text {nd }}$ year & 2.115 \\
& & $3^{\text {rd }}$ year & 1.738 \\
& & $4^{\text {th }}$ year & 1.830 \\
\hline Design & Civil & $4^{\text {th }}$ year & 1.907 \\
& Elec. \& Comp. & $2^{\text {nd }}$ year & 2.699 \\
& & & \\
\hline
\end{tabular}

\begin{tabular}{|l|ll|l|}
\hline & & $3^{\text {rd }}$ year & 1.904 \\
& & $4^{\text {th }}$ year & 2.132 \\
\hline Use of & Civil & $4^{\text {th }}$ year & 1.858 \\
Engineering & Elec \& Comp. & $2^{\text {nd }}$ year & 2.383 \\
Tools & & $3^{\text {rd }}$ year & 2.067 \\
& & $4^{\text {th }}$ year & 2.154 \\
\hline Individual and & Civil & $4^{\text {th }}$ year & 1.858 \\
Teamwork & Elec. \& Comp. & $2^{\text {nd }}$ year & 1.654 \\
& & $3^{\text {rd }}$ year & 1.531 \\
& & $4^{\text {th }}$ year & 1.745 \\
\hline Communication & Civil & $4^{\text {th }}$ year & 1.845 \\
Skills & Elec. \& Comp. & $2^{\text {nd }}$ year & 2.051 \\
& & $3^{\text {rd }}$ year & 1.784 \\
& & $4^{\text {th }}$ year & 1.8 \\
\hline Professionalism & Civil & $4^{\text {th }}$ year & 2.028 \\
& Elec \& Comp. & $2^{\text {nd }}$ year & 2.042 \\
& & $3^{\text {rd }}$ year & 1.693 \\
& & $4^{\text {th }}$ year & 1.786 \\
\hline Impact of & Civil & $4^{\text {th }}$ year & 2.053 \\
Engineering on & Elec \& Comp. & $2^{\text {nd }}$ year & 2.562 \\
Society and & & $3^{\text {rd }}$ year & 2.051 \\
Environment & & $4^{\text {th }}$ year & 2.33 \\
\hline Ethics and & Civil & $4^{\text {th }}$ year & 2.163 \\
Equity & Elec \& Comp. & $2^{\text {nd }}$ year & 2.667 \\
& & $3^{\text {rd }}$ year & 2.347 \\
& & $4^{\text {th }}$ year & 2.04 \\
\hline Economics and & Civil & $4^{\text {th }}$ year & 2.075 \\
Project & Elec. \& Comp. & $2^{\text {nd }}$ year & 2.807 \\
Management & & $3^{\text {rd }}$ year & 2.219 \\
& & $4^{\text {th }}$ year & 2.207 \\
\hline Lifelong & $4^{\text {th }}$ year & 1.85 \\
Learning & Elec. \& Comp. & $2^{\text {nd }}$ year & 2.037 \\
& $3^{\text {rd }}$ year & 1.650 \\
& $4^{\text {th }}$ year & 1.739 \\
\hline
\end{tabular}

* Converted from a 4-point Likert scale (ECE) to align with Civil survey scale (5-point Likert).

4-point Likert scale:

1=Strongly agree, $2=$ Slightly agree, $3=$ Slightly disagree, $4=$ Strongly disagree

\section{DISCUSSION}

Civil Engineering graduates indicated, en masse, that they agreed with a perceived ability of each of the twelve attributes. The survey elicited great response from the graduating class, and can be used to make generalizations about the learned curriculum of UBC Civil Engineering. This, however, highlights several sections of the lived curriculum that must be explored in more depth. Firstly, the breadth and depth of the Civil Engineering curriculum allows students flexibility to select from a myriad of courses, which creates the possibility of vastly different learning experiences for students. The limitation of this survey 
is the inability to hone in on learning experiences that shaped students' perception of their ability. With this limitation in mind, there are still very important discussions that can be had regarding student attribute development.

There was a substantial difference is mean scores between all Electrical and Computer Engineering years. This coincides with the notion that students' perceptions of their graduate attribute abilities is developed over time. It should also be noted that both Electrical and Computer Engineering and Civil Engineering have program options, which can create a unique set of courses for each student. The variance between years can be attributed to course selection, course electives, program options, and lived curricular experience. Further research is required to explain the gradient of graduate attribute development across program levels and options.

Students that identified their program as "BASc + Co-op" had a higher perceived ability in Teamwork than in Project Management. In contrast, students who identified their program as "BASc" felt more strongly about their perceived ability in Project Management than Teamwork. This highlights an interesting dichotomy; students who experienced a drastically different lived curriculum (i.e. Co-op) have their perception of their abilities altered. This concept lends itself to the notion that student perception of graduate attributes can be evaluated at the planned and lived curricular levels. It should also be noted that during the pre-survey focus groups, several students had expressed concern regarding authentic teamwork experiences and assessment of individual versus teamwork skill development.

The development of a survey tool that aims to capture the lived curriculum of an undergraduate engineering student must strike a balance between survey items that students can associate with, and attribute constructs which may stem from program learning objectives. Although the survey instrument was developed with both programs in mind, alterations to the survey were necessary to address program-specific nuances. These can include degree of teamwork versus individual work, project type and presentation style, and range of technical courses. In this regard, student surveys of graduate attributes must be tailored to each program. Any data analysis seeking correlation between programs or levels should ensure that the survey items are identical and internally reliable within the attribute survey construct.

\section{CONCLUSION}

Student perception of graduate attributes is an insightful tool for understanding the extent to which students have experienced the planned curriculum. An analysis of students' perceived ability within a set of attributes creates a holistic overview of the abilities of a graduating class of engineers. This information can be captured using a validated survey tool, and adapted to fits the distinct program requirements. The primary benefit of a student survey is insight into the effectiveness of planned curriculum, and the perceived ability of graduating students. A secondary benefit of a student survey is the ability to highlights advantages of separate program options, specifically when addressing individual graduate attributes. Future research can develop a more comprehensive, qualitative survey instrument that captures both the planned and lived engineering curriculum.

\section{Acknowledgements}

This work was supported by Teaching Learning Enhancement Fund, the UBC Civil Engineering department and the UBC Computer and Electrical Engineering department.

\section{References}

[1] Glynn, S. \& Koballa, M. (2006). Motivation to Learn in College Science. Chpt. 3 in Mintzes, J. \& Leonard, W. (ed.s), Handbook of College Science Teaching, Danvers, NSTA Press.

[2] Johnson, M.H. and Munakata, Y. (2005). Processes of change in brain and cognitive development. TRENDS in Cognitive Science, 9: 152-158.

[3] Kuh, G. D. (2003). What we're learning about student engagement from NSSE. Change, 35 (2): 24-32.

[4] Pintrich, P. (2002). The Role of Metacognitive Knowledge in Learning, Teaching, and Assessment. Theory and Practice, 41(4): 219 - 225.

[5] Southerland, S.A., Sinatra, G.M., Matthews, M.R. (2001). Belief, Knowledge, and Science Education. Educational Psychology Review, 13 (4): 325 - 351.

[6] Duderstadt, J. J. (2008) Engineering for a Changing World: A Roadmap to the Future of Engineering Practice, Research, and Education. The Millennium Project, The University of Michigan, Ann Arbor.

[7] Heidebrecht, A. (1999). Evolution of Engineering Education in Canada. Canadian Academy of Engineering. Retrieved from: http://www.acad-enggen.ca/publis/e/Evolution a.cfm 
[8] Hubball, H.T., \& Pearson, M. (2010). Grappling with the complexity of undergraduate degree program reform: Critical barriers and emergent strategies. Transformative Dialogues, 3(3).

[9] Wolf, P. (2007). A model for facilitating curriculum development in higher education: A faculty-driven, data-informed, and educational developer-supported approach. New Directions for Teaching \& Learning, (112), 15-20.

[10]Hubball, H.T., \& Burt, H. (2007). Learning Outcomes and Program-level Evaluation in a 4-Year Undergraduate Pharmacy Curriculum. American Journal for Pharmaceutical Education, 71(5), Article 90, 1-8.

[11] American Educational Research Association, American Psychological Association, \& National Council on Measurement in Education (1999). Standards for educational and psychological testing. Washington, DC: American Educational Research Association.

[12] Goodwin, L. D. \& Leech, N. L. (2003). The meaning of validity in the new standards for educational and psychological testing: Implications for measurement courses. Measurement and Evaluation in Counseling and Development, 36, 181-191.

[13] Andres, L. (2012). Designing and doing survey research. London: Sage.
[14] Hinkin, T. R. (1998). A Brief Tutorial on the Development of Measures for Use in Survey Questionnaires. Organizational Research Methods, 1(1), 104-121. doi:10.1177/109442819800100106

[15] Widaman, K. (1993). Common factor analysis versus principal component analysis: Differential bias in representing model parameters? Multivariate Behavioural Research, 28, 263-311.

[16] Russell, D. W. (2002). In Search of Underlying Dimensions: The Use (and Abuse) of Factor Analysis in Personality and Social Psychology Bulletin. Personality and Social Psychology Bulletin, 28(12), 1629-1646. doi:10.1177/014616702237645

[17] O'Connor, B. (2000). SPSS and SAS programs for determining the number of components using parallel analysis and Velicer's MAP test. Behaviour Research Methods, Instrumentation, and Computers, 32, 396-402.

[18] Kotrlik, J. W. K. J. W., \& Higgins, C. C. H. C. C. (2001). Organizational research: Determining appropriate sample size in survey research appropriate sample size in survey research. Information technology, learning, and performance journal, 19(1), 43.

[19] Mohamed, A., Fatihah, S., \& Ismail, A. H. (2012). Graduate Students' Perspectives on Study Environment Based on Exit Survey. Asian Social Science, 8(16), 200-208. doi:10.5539/ass.v8n16p200 